Title: INTRODUCING A DESIGN EXIGENCY TO PROMOTE STUDENT

LEARNING THROUGH ASSESSMENT: A CASE STUDY

Authors

Laurie A. Grealish RN, $\mathrm{PhD}^{1,2}$

Julie M. Shaw RN, $\mathrm{PhD}^{1,2}$

${ }^{1}$ Gold Coast Hospital and Health Service

Hospital Boulevard

SOUTHPORT Qld 4215

${ }^{2}$ Griffith University, Gold Coast campus

Parklands Drive

SOUTHPORT Qld 4215

Corresponding author

Laurie Grealish

Room 2.05c, Building G01

Griffith University, Parklands Drive

SOUTHPORT Qld 4215

Email: 1.grealish@griffith.edu.au

Phone: +61 755529558

Facsimile: +61 755528526

Word count: 4270

\title{
Contributors and Acknowledgements
}

The authors would like to acknowledge Professor Amanda Henderson and Ms Lyn Armit who provided feedback on earlier versions of this manuscript. 
Title: INTRODUCING A DESIGN EXIGENCY TO PROMOTE STUDENT

LEARNING THROUGH ASSESSMENT: A CASE STUDY

\begin{abstract}
Background Assessment technologies are often used to classify student and newly qualified nurse performance as 'pass' or 'fail', with little attention to how these decisions are achieved. Examining the design exigencies of classification technologies, such as performance assessment technologies, provides opportunities to explore flexibility and change in the process of using those technologies.
\end{abstract}

Objective Evaluate an established assessment technology for nursing performance as a classification system.

Methods A case study analysis that is focused on the assessment approach and a priori design exigencies of performance assessment technology, in this case the Australian Nursing Standards Assessment Tool 2016.

Findings Nurse assessors are required to draw upon their expertise to judge performance, but that judgement is described as a source of bias, creating confusion. The definition of satisfactory performance is 'ready to enter practice'. To pass, the performance on each criterion must be at least satisfactory, indicating to the student that no further improvement is required. The Australian Nursing Standards Assessment Tool 2016 does not have a third 'other' category, which is usually found in classification systems.

Discussion Introducing a 'not yet competent' category and creating a two-part, mixed methods assessment process can improve the Australian Nursing Standards Assessment Tool 2016 assessment technology. Using a standards approach in the first part, judgement is valued and can generate learning opportunities across a program. Using a measurement approach in the second part, student performance can be 'not yet competent' but still meet criteria for year level performance and a graded pass. 
Conclusion Subjecting the Australian Nursing Standards Assessment Tool 2016 assessment technology to analysis as a classification system provides opportunities for innovation in design. This design innovation has the potential to support students who move between programs and clinicians who assess students from different universities.

Keywords: assessment, clinical competence, measurement, standards, student nurse. 


\section{Introduction}

Clinical competence for entry to practice nurses has become an important international concern for regulatory, education and health service providers, as well as students. The direct effects of clinician competence on consumer outcomes justify the overwhelming interest in nurse competence. And yet, the highly heterogeneous nature of health services has made the search for a single, simple to use assessment technology challenging (Cowan et al, 2005; Norman et al., 2002) and not recommended (English et al., 2014).

Competency assessment instruments often emerge as a 'black box' technology, “... a tool that is no longer questioned, examined or viewed as problematic, but is taken for granted” (Fujimura, 1996, p. 23). However, given the lack of existing evidence of how the standards and associated assessment technologies are used to make decisions about competence (Terry et al., 2017), it is timely to ‘open the box' for analysis. As a classification system, one that classifies nurse performance, competency assessment instruments are suffused with ethical and political values related to accountability, safety, professionalism and others. By remembering the ethical and political values of a black box technology, spaces for change and flexibility can be explored (Bowker \& Star, 2000). This case study aims to describe how assessment technologies, used to classify student nurse performance, can be improved.

\section{Literature Review}

\section{Competence}

While there is general agreement that competency should be assessed over time (Franklin \& Melville, 2015), competence and competency are not well defined in the nursing literature. In a concept analysis, Tilley (2008) concluded that a lack of a clear definition has impeded 
progress towards assessment of effective practices in nursing. In Australia, competence emerged as a concept in nursing in the late $20^{\text {th }}$ century, defined as:

... the combination of attributes (knowledge, capabilities, skills, attitudes) structured into competencies which enable an individual or a group to perform a role or set of tasks to an appropriate level or grade of quality or achievement (that is, an appropriate standard) in a particular type of situation, and thus make the individual or group competent in that role (Preston \& Walker 1993, p.116).

While the decision to adopt competence as an organising framework for the profession was hotly debated in the 1990s (Alspach, 1991; Ashworth \& Morrison 1991; Cheek et al., 1995; Chambers, 1998; McAllister, 1998; Milligan, 1998; Chapman, 1999), the use of competence and competency assessment by the Australian and international nursing communities has rapidly increased since 1988 (Chiarella et al., 2008), becoming ubiquitous, with other ways of conceptualising nursing practice rendered invisible.

Expressed as standards, competencies codify and prescribe a particular set of ethics and values (Star \& Lampland, 2009). Performance that is consistent with professional expectations is often determined within highly localised teams across a variety of health settings; that is, professional expections may vary dependent on context. Students must quickly assess and negotiate the shared values within each team in order to access learning opportunities (Levett-Jones et al., 2009), which can lead to performance that meets the standard for a pass grade, so they can continue in the program. Students who are unable to negotiate the ethics and values of the health team in which they are immersed for clinical learning may experience poor outcomes including confusion, ineffective team work and an inability to demonstrate competence.

\section{Using assessment technologies}


From the early development of assessment technologies, there was a focus on issues of reliability and validity (Donoghue \& Pelletier, 1991) and this focus continues today (Wu et al., 2015). However, while most literature is focused on designing valid and reliable assessment technology, a review of competence assessment instruments in nursing found that context is absent in these technologies (Windsor et al., 2012). In their qualitative study of mentors, Cassidy and colleagues (2017) found that a collective account of performance standards exist within nursing teams, which can be helpful when considering student performance that is borderline, suggesting that while implicit, context is actively considered by nurses working with students. One way of addressing the nuanced differences presented by context has been to develop competency guides (Brown et al., 2017) or sets of behavioural cues (Ossenberg et al., 2016). While these go some way to address the variability in practice settings, these guides are very long documents which can be a deterrent to use.

Inter-rater reliability is an important concern in the use of assessment technologies and refers to the degree that two or more independent assessors, apply the same value to the asset being measured (Kelly, 2005). At the time that assessment technologies for competency assessment were emerging (Donaghue \& Pelletier, 1991), clinical supervisors and students were supernumerary and one supervisor worked with six students (Grealish \& Carroll, 1997). In this configuration, there was time to train supervisors to use the assessment technology, and for supervisors to assess the students over time, providing comprehensive feedback on their performance. In contrast to this, students undertaking practice experiences today enter the field in a variety of placement models from preceptorship and mentorship to clinical supervision and Dedicated Education Units, with variable levels of consistent support and assessment (Butler et al., 2011; English et al., 2014). One common element in these models is time constraints, which limit opportunities 
for feedback (Hutchison et al., 2016; Burke et al., 2016). In light of the changes in clinical placement provision, the search for the best assessment technology has shifted from valid and reliable to include other features such as, meaningful to busy assessors (English, 2011; Ossenberg et al., 2016).

The use of assessment technologies has subtly shifted. Initially the instruments were promoted as a framework for the provision of feedback to support student learning (Donoghue \& Pelletier, 1991) but more recently, they have been used to 'sign off' students as registration ready (Gallagher et al., 2012). For nurses who work with nursing students, this shift has resulted in a tension between providing feedback and making a summative judgement (Gallagher et al., 2012; Hutchison et al., 2014; Wu et al., 2015). In some places, this tension in the use of the instrument is addressed through an explicit package that includes a learning contract (Zasadny \& Bull, 2015). These tensions create problems for nurses who work with students. They value humanist elements of the process of assessment, providing feedback and reciprocity of learning (Burke et al., 2016), however this can create problems for the assessment of students who have borderline or poor performance (Cassidy et al., 2017).

\section{Approaches to assessment}

There are two dominant approaches to assessment in higher education: measurement and standards (Biggs, 2005). In a measurement approach, knowledge is quantitative and better learners know and do more, grades are associated with the maximum number possible, and assessment is a stand-alone activity, unrelated to teaching (Biggs, 2005). In a standards approach, student performance is assessed against a standard that is set at an acceptable level (Biggs, 2005). The standards approach can accommodate different performances in different situations or circumstances and teachers are positioned to make 
judgements about performance quality (Biggs, 2005). Reliability is grounded differently in each. In the measurement approach, reliability is grounded in the instrument and in a standards approach, reliability is grounded in the assessor’s judgement (Biggs, 2005).

When judgement is central to assessment, students can be engaged to make judgements about their learning as a normal part of the assessment activities, rather than an 'add-on' (Boud, 2007). In this way, the discourse of informing judgement has a dual focus on the learning needs of the student as well as the legitimate need of others to have an account of student learning outcomes (Boud, 2007). In this example of nursing, 'others' include regulators, universities and health services.

Grades are essential in the measurement assessment approach (Biggs, 2005). In a standards assessment approach, grades can be used when clear grade descriptors are present (Boud, 2007). When performance is graded, there are opportunities for the assessor to work with the student to improve future performance, identify future learning goals and become a lifelong learner and clinician. Identifying future goals is consistent with health workplaces that foster continuous improvement (Boud \& Molloy, 2013) and may increase rapport between the learner and the assessor, generating conditions that enhance learning (Molloy, 2010).

Students are consistently found to be focused on the process of assessment (Bradshaw et al., 2012; Heaslip \& Scammel, 2012), with strategies to support students to judge their own learning beginning to emerge (Boud \& Molloy, 2013). How assessment technologies can engage students in assessing their own performance, rather than simply focusing on the processes is a significant challenge.

In summary, while the research into assessment technologies has continued to advance, studies into how these technologies are used to make judgements about students’ performance and more importantly whether they pass or fail have not been explored. 
Competency assessment technologies are classification systems. Classification theory assumes that categories are non-existent until socially constructed, and even then, most lay people are unaware of the multitude of categories that exist in the social world (Bowker \& Star 2000). There are three design exigencies in classification systems: the balancing act of classifying work by incorporating ambiguity is recognised; the voice of the classifier is held present; and the system is sensitive to exclusions (Bowker \& Star 2000, p. 325). This research aims to evaluate one well established assessment technology as a classification system. Through this evaluation, recommendations for improvements in assessment technology are provided.

The ANSAT 2016 assessment technology was selected as the classification system for analysis. The ANSAT was originally developed in Australia as a single instrument to assess student nurse competence in 2014 and was found by the developers to be a valid assessment tool (Ossenberg et al., 2016). The ANSAT assessment technology was developed in close alignment with the national registered nurse regulatory standards, and through this association aimed to integrate performance assessment across many organisations and states (Grealish, 2012). In 2016, the ANSAT was adapted to the recently published and current Australian Registered Nurse Standards for Practice (2016). This makes the ANSAT 2016 a powerful social and political technology, worthy of closer evaluation. The ANSAT 2016 comes with a Resource Manual, a list of Performance Cues, and regular updates (see: http://www.ansat.com.au/). As an example of a classification system, the ANSAT 2016 classifies student performance as satisfactory (competent) or not (not competent). Performance that is judged to be satisfactory, good or excellent allows the student to progress in the clinical stream of the degree program, thereby working towards a valued career in nursing.

\section{Methods}




\section{Design}

A case study approach for the evaluation of the ANSAT 2016 was adopted (Yin 2009). The evaluation process included two major steps: the first was a review of the technology to assess performance quality (ratings) reliability, and grading (Biggs, 2005); followed by a second step, a review that focused on design exigencies (Bowker \& Star, 2000).

\section{Data collection \& analysis}

The ANSAT 2016 Clinical Placement Assessment Tool (ANSAT 2016_v1.2_160629) and Resource Manual (Developed 13 March 2014_revised 30 June 2016) were printed and reviewed. In the initial review, the two authors (LG, JS) independently read and reread the documents, with attention to key features of the assessment approach focused specifically on performance quality (ratings), reliability, and grading. Following this initial review, the two authors discussed their findings and negotiated agreement on the quality, reliability and grading of the technology .

The first author (LG) conducted the secondary analysis that focused on the three design exigencies of Classification System Design theory a priori: “incorporating ambiguity in the balancing act of classifying; classifier's voice is held present; and the system is sensitive to exclusions” (Bowker \& Star, 2000, p. 325). The second author (JS) reviewed and validated the secondary analysis.

The design of assessment technologies is recognized as complex work, that is socially and politically loaded (Windsor et al., 2012). As such, the analysis of one assessment technology over others creates ethical and social concerns for the developers of that technology. At the same time, technology that is as important to nursing and community well-being as competency assessment technology is open to peer review and critique In consideration of fairness and the spirit of peer review, the findings were 
shared with the senior developer of the assessment technology whose feedback was considered before this manuscript was submitted for publication.

\section{Findings}

The following findings are described and discussed below - performance quality, reliability, grading and the design exigencies of the ANSAT 2016 as a classification system used to grade clinical performance. The processes for judging performance quality, using 'ready to enter practice' as the standard for pre-service performance could create confusion for students and those assessing their performance and that a third, 'not yet competent' category may go some way to address this short-coming.

\section{Performance quality}

The minimal performance quality at each level of the program, years 1,2 and 3 is considered to be satisfactory or a score of 3, which is consistent with the beginning registered nurse. Specifically, the satisfactory quality of performance (score of 3) is found in the following excerpts:

- The Global Rating Scale uses five points: excellent (5), good (4), satisfactory (3), limited (2), and unsatisfactory (1) (Resource Manual, p. 14)

- The minimum beginning registered nurse standard is - satisfactory (Resource Manual, p. 15).

- Satisfactory is described as “.... an adequate student will be safe and capable. A satisfactory student would typically be able to:

o Manage a variety of patients with relatively uncomplicated needs, such that the patient/client's major problems are identified, major goals established and treatment is completed safely and effectively within a reasonable timeframe

o Have awareness of their limitations and when to seek assistance” (ANSAT Resources Manual, p.15)

- The score ' 3 ' (satisfactory) is used “... when the student has demonstrated performance that is the minimum performance considered necessary to achieve safe beginning level practice” [i.e. newly qualified nurse] (Resource Manual, p. 33). 
Students are required to demonstrate satisfactory qualities for each domain area, where scoring 1 or 2 for any assessment items means “...they have not met the requirements for that domain and as such cannot be recommended by the assessor to have passed the placement” (Resource Manual, p. 34). A performance of a quality deemed 'fail' is at a score of 1 or 2 , and characterised by students who:

- Are unsafe with clients;

- Demonstrate unsatisfactory of limited competence (marked inconsistency);

- Only perform safely and appropriately with substantial supervision and/or assistance;

- Demonstrate limited understanding and application of fundamental knowledge and skills; and/or

- Have significant gaps and/or inaccuracies in knowledge and skills (Resource Manual, p. 28).

Performance quality at the higher levels of 4 and 5 include "manage a variety of patients, including complex patients, meeting the minimum acceptable standard at a skilled level” (Resource Manual, p. 15) and incorporating aesthetic elements of independence, sensitivity, efficiency, flexibility, adaptability, and insight as excellent (level 5) quality (Resource Manual, p. 15).

There is also a 'not assessed' option for each of the 23 criteria. In the Resource Manual, it is emphasised that "if an item is not assessed it is not scored, and the total ANSAT score will be adjusted for the missed item” (p. 16). However, no limitations on the number of criteria that are not assessed in order to determine a fail grade are addressed, nor are there guidelines on determining limitations of non-assessed items.

In summary, there are only two categories produced by the ANSAT assessment technology: ‘pass’ or 'fail’. Performance quality on assessment criteria must be satisfactory (level 3) in order to be categorised as a 'pass'. Students who achieve less than a satisfactory quality of performance on any of the 23 criteria would fail the placement experience and not be able to progress in the Bachelor of Nursing program, yet a student who was not assessed 
in any number of the 23 criteria may still pass the clinical placement. These two identified aspects constitute points of divergence in the useability of the ANSAT 2016. The former introduces the possibility of assessor bias. The latter raises inconsistencies, in terms of the comparison of student performances across the course, when placements afford different opportunities to perform for the purpose of assessment.

Reliability

Assessment is subjective highlighting the importance of inter-rater reliability of the ANSAT, which unfortunately was not assessed in the validation of the ANSAT 2014 (Ossenberg et al, 2016). In addressing inter-rater reliability, the Resource Manual (2016) informs the reader that it is "important that students assessed by one assessor receive a similar rating if assessed by a different assessor” ( p. 31), emphasising that the instrument can qualify performance if the assessors know how to use it.

The role of the assessor's judgement is recognised as a source of possible bias when using the ANSAT 2016 technology (Resource Manual, pp. 25-26). The possible biases include rater bias, halo effect, devil (horn) effect, leniency, central tendency, anchoring, and outcome bias (Resource Manual, pp. 25-26). To avoid bias, assessors are encouraged to undertake regular training, follow a specific assessment process, collaborate with the university and the workplace, and consult an independent assessor (Resource Manual, p. 31).

\section{Grading}

How the ANSAT 2016 can provide a grade for clinical performance is discussed in the Resource Manual. Firstly, the items (n=23) within each of the seven standards of the ANSAT 2016 are scored. The Global Rating Scale (GRS) provides a final performance quality description as noted in performance quality. The relationship between item scores and GRS scores is left ambiguous - open for university staff interpretation. For example, 
"Universities might consider both item and GRS scores when deciding whether a student would benefit...” (Resource Manual, p. 14). The ANSAT 2016 has a raw score of 115 and again discretion to the universities is provided in the resource guide, “...universities may apply additional hurdle requirements on certain items, and may have different weightings for the ANSAT component of a clinical placement/course result” (p. 33).

Feedback to students is not specifically discussed in the Resources Manual, however the use of the ANSAT 2016 behavioural cues is encouraged to provide examples of behaviours that are needed to demonstrate satisfactory performance (p. 35). It is noted that feedback to students should “...describe the behaviour that the student needs to demonstrate in order to achieve a higher grade” (Resource Manual, p. 33). These approaches to feedback indicate that a standards assessment approach is used, with the quality of performance and criteria emphasised in feedback to inform the student of how to develop further.

\section{$\underline{\text { Design exigencies }}$}

The balancing act of classifying work by incorporating ambiguity is recognised in classification systems (Bowker \& Star, 2000). In the ANSAT 2016 assessment technology, the relationship between (1) the scores on the 23 criteria and (2) the Global Rating Scale is left open to interpretation by universities, excluding the assessor in the process. The final classification, pass or fail grade, is not in the control of the assessor; the assessor makes a recommendation. In the process of making a recommendation, both the assessor and student are encouraged to gather evidence from practice to support claims about quality on each of the 23 criteria (Resource Manual, p. 10). There is scope for the assessor and student to discuss their observations of performance and compare to the behavioural cues provided in the package (Behavioural Cues) before a final decision is made.

The second design exigency is that the voice of the classifier is present (Bowker \& Star, 2000, p. 325). The 'classifier' in the case of students, is the university, which is 
clearly identified as a stakeholder (Resource Manual, p. 7). However, who finally classifies the quality of performance or the GRS, whether it is unsatisfactory, limited, satisfactory, good, or excellent, is not explicit. Grading of performance is left open for staff in the universities to decide. In this way, the voice of the classifier is not visible to the student and assessor, with little guidance about how the performance quality is graded.

The third and final design exigency is that the system is sensitive to exclusions (Bowker \& Star, 2000, p. 325). The ANSAT 2016 assessment technology has no exclusions, the quality of performance at satisfactory (3) or above is a pass, "the minimum performance considered necessary to achieve safe beginning level practice” (Resource Manual, p. 33). Performance at unsatisfactory (1) or limited (2) are not considered a pass. When specific criteria are not observed, often due to limited opportunities for practice, then those are marked as 'not assessed' and not counted in the final rating (Resource Manual, p. 16). The lack of a third 'other' category, means that students who are borderline in their performance are classed either as 'fail' or 'pass'.

\section{Discussion}

A standards approach to assessing competence has dominated Australian nursing (Chiarella et al., 2008) and as an example of assessment technology, the ANSAT 2016 appropriately reflects the national standards. However, the ANSAT 2016 is not simply an assessment technology, it is also a classification system, classifying student performance as pass (competent) or fail (not competent), with significant ethical and political outcomes for the students, the university and health services. This review of the ANSAT 2016 assessment technology raises issues around: (1) the value of judgement in making assessment decisions, (2) the need for a new, 'other', category, and (3) the need 
for nationally standardised grading to support students to learn through assessment while creating national consistency in rating student (learner) performance.

In standards approaches to assessment, judgement about performance quality is valued and reliability is grounded in the assessor’s judgement (Biggs, 2005). The ANSAT 2016 appears to use a standards-based assessment approach, with the assessor collecting information about student performance on a variety of activities and then forming a judgement about the standard of practice. However, the original instrument has been subjected to validation as a measurement tool (Ossenberg et al., 2016). Used as a measurement tool, assessor judgement is considered to be a potential source of bias. This implicit paradox, requiring assessors to judge performance in a standards assessment approach and then describing that judgement as a source of bias, is problematic for assessors. Further to this, assessors are not the final arbiters of the classification decision of pass or fail; this is the university's decision, indicating less value for assessor judgement.

One way to address this paradox is to place judgement as central to the assessment process. Consistent with Boud (2007), we suggest that the feedback cycle process described in the Resource Manual (p. 10) could become an organising framework for the assessment process, with more guidance on how to include students in making judgements about their learning as a normal part of assessment activities rather than an ‘add-on'. In this way, developing judgements about performance using the ANSAT 2016 and associated performance cues, becomes a valued part of the assessment process rather than a source of bias. When judgement is accepted as a necessary part of the assessment process, the assessor can make the classification decision about the performance in the practice site rather than deferring responsibility to the university. 
A key design exigency in classification systems, the requirement for an 'other' category, is not met in the ANSAT 2016. The ANSAT 2016 requires that students perform at a satisfactory level in order for the performance to be classified as 'pass' (competent). Scoring less than 3 on any of the 23 items would lead to a performance being categorised as 'fail' (not competent), whereas non-performance of some items due to inadequate opportunities can still lead to a pass grade.

In the Resource Manual (2016), satisfactory is defined as the minimum registered nurse entry-to-practice performance (p. 15). This is another paradox in the ANSAT 2016 assessment technology: the student is learning to be a nurse, and therefore assumed to be not ready (competent) for registered nurse practice, but must meet the standard for entryto-practice in order to gain a 'pass' (competent) grade. When performance is satisfactory, and satisfactory is defined as entry-to-practice competence, there is little scope for conversations about continuous improvement. Further, when confronted with the significant decision of recommending 'pass' or 'fail', assessors will err on the side of 'pass' due to the consequences of a 'fail' grade for the student. This decision signals to the student that no further improvement is required.

The description of a performance that indicates a fail grade is described in the Resource Manual (p. 27). However, there is little capacity in the current instrument design for nuanced judgements about performance that approximates graduate level practice. Nor is there a requirement that all criteria are observed in order to achieve a pass grade. We suggest an additional category for the ANSAT 2016 assessment technology - 'not yet competent'. If nursing students are classified as 'not yet competent' as they progress through the program, there are opportunities to have 'unsatisfactory' or 'limited' judgements of performance or 'not assessed' on some criteria but still exhibit a satisfactory performance overall. 
In order to introduce the 'not yet competent' category, we suggest a two part, mixed methods, assessment process. The initial assessment, whereby nurse assessors judge student performance against the 23 criteria is a standards based approach. The second part, classification of overall performance is a measurement approach. A grading system, identifying the number of criteria that must be met for each level of the program, provides clarity to students and assessors regarding what constitutes a satisfactory performance (See Table 1). This process clearly identifies the need for all 23 criteria to be met at a satisfactory level of performance on the final placement.

Please insert Table 1 about here

With the recommended graded performance across the program, there are opportunities for the student and assessor to identify areas for learning in future placements, as well as develop skills in lifelong learning - identifying limitations and planning how to address these. The expected benefits of this approach, increased rapport between learner and assessor (Molloy, 2010) and a foundation for the process of continuous improvement (Boud \& Molloy, 2013), could be tested through further research.

The two-part mixed methods assessment process can provide national consistency in rating student (learner) performance. It can provide a method for making decisions on performance across the three-year program. Given that the nursing profession regulates Bachelor of Nursing curricula, the introduction of consistent requirements for performance across year groups contributes to standardising assessment of clinical practice. With the recommended changes, the ANSAT 2016 can be used to assign 
specific grades to student performance using the earlier hurdle requirements for a pass and global rating scores to calculate the grade. For an example, refer to Table 2.

Please insert Table 2 about here.

We suggest that this two part approach, mixing the methods of measurement for grading following the standards assessment process, provides a minor, but important design innovation to the ANSAT 2016 technology. This innovation produces a consistency across programs that can facilitate student movement between programs and provides a clear framework for nurse assessors to monitor student learning for students in the workplace from different programs. A graded approach to classification, that recognises that students are 'not yet competent' creates rich opportunities for student learning, values nurses' judgement in the assessment process, and provides an emerging national system for performance assessment.

\section{Conclusion}

The analysis of assessment technologies, which classify nursing performance, is important. These classification technologies can prevent a student from reaching graduation, stop a newly qualified nurse from securing a continued contract, and stop a registered nurse from practising on the grounds of being not competent. Individual and organisational livelihoods are dependent upon this classification system. In this case study, we found that the ANSAT 2016 assessment technology has the potential for significant benefit in standardising the assessment of student nurse practice in a range of health settings. Opening the black box technology, and identifying two paradoxical 
characteristics of the ANSAT 2016, provides an opportunity to further develop this assessment technology for national implementation.

Drawing upon theory from classification systems design, we suggest modifications to incorporate a third category, 'not yet competent' to increase sensitivity to exclusions. The modifications include a two part assessment process that (1) reframes assessor judgement as a source of feedback rather than a source of bias by adopting a standards assessment approach in part one; and (2) uses a grading system to describe the level of performance required at each stage of the Bachelor of Nursing Program. Research into the feasibility of this design exigency is required before recommending widespread change. 


\section{References}

Alspach, G. 1992. Concern and confusion over competence. Critical Care Nurse, 12(4), 9-11.

Australian Nursing Standards Assessment Tools (ANSAT) 2016 v1. Retrieved 1st March, 2017 from http://www.ansat.com.au/home/tools

ANSAT Behavioural Cues, 2016. Retrieved 1st March, 2017 from http://www.ansat.com.au/home/tools

ANSAT Resource Manual, 2016. Retrieved 1st March, 2017 from http://www.ansat.com.au/home/assessment-manual

Ashworth, P., Morrison, P. 1991. Problems of competence-based nurse education. Nurse Education Today, 11(4), 256-260. http://dx.doi:10.1016/0250-6917(91)90087-Q

Biggs, J. 2005. Teaching for Quality Learning at University, 2nd ed. Open University Press, Berkshire, U.K.

Boud, D. 2007. The context of assessment. In D. Boud and N. Falchikov (Eds) Rethinking Assessment in Higher Education: Learning for the long-term. Routledge, London, U.K.

Boud, D., Molloy, E. 2013. Rethinking models of feedback for learning: the challenge of design. Assessment \& Evaluation in Higher Education 38(6), 698-712. http://dx.doi:10:1080/02602938.2012.691462

Bowker, G. Star, S. L. 2000. Sorting things out: Classification and its consequences. MIT Press, Cambridge, Massachusetts.

Bradshaw, C., O'Connor, M., Egan, G., Tierney, K., Butler, M.P., Fahy, A., Ruohy, D., Cassidy, I., Qillinan, B., McNamara, M.C., 2012. Nursing students' views of clinical competence assessment. British Journal of Nursing 21(15), 923-927. http://dx. doi:10.12968/bjon.2012.21.15.923

Brown, R.A., Crookes, P.A., 2017. How do expert clinicians assess student nurses competency during workplace experience? A modified nominal group approach to devising a guidance package. Collegian 24(3), 219-225.

http://dx.doi:10.1016/j.colegn.2016.01.004

Butler, M.P., Cassidy, I., Quillinan, B., Fahy, A., Bradshaw, C., Tuohy, D., O'Connor, M., McNamara, M.C., Egan, G., Tierney, C., 2011. Competency assessment methods - Tool and processes: a survey of nurse preceptors in Ireland. Nurse Education in Practice. 11(5), 298-303. http://dx.doi:10.1016/j.nepr.2011.01.006

Burke, E., Kelly, M., Byrne, E., Chiardha, T.U., McNicholas, M., Montgomery, A., 2016. Preceptors' experiences of using a competency assessment tool to assess undergraduate nursing students. Nurse Education in Practice 17, 8-14. http://dx.doi:10.1016,j.nepr.2016.01.004

Cassidy, S., Coffey, M., Murphy, F., 2017. 'Seeking authorization': a grounded theory exploration of mentors' experiences of assessing nursing students on the borderline of achievement of competence in clinical practice. Journal of Advanced Nursing 73(9), 2167-2178. http://dx.doi:10.1111/jan.13292

Chambers, M. A. 1998. Some issues in the assessment of clinical practice: a review of the literature. Journal of Clinical Nursing, 7(3), 201-208.

http://dx.doi.10.1046/j.1365-2702.1998.00121.x 
Chapman, H. 1999. Some important limitations of competency-based education with respect to nurse education: an Australian perspective. Nurse Education Today, 19(2), 129-135. doi:0.1054/nedt.1999.0620

Cheek, J., Gibson, T., Gilbertson, J. 1995. Competencies: really or merely useful? In G. Gray and R. Pratt, eds. Issues in Australian nursing, 4th ed. Churchill Livingstone, Melbourne, Australia, pp. 29-44.

Chiarella, M., Thoms, D., Lau, C., McInnes, E. 2008. An overview of the competency movement in nursing and midwifery. Collegian, 15(2), 45-53. http://dx.doi:10.1016/j.colegn.2008.02.001

Cowan, D., Norman, I., Coopamah, V. 2005. Competence in nursing practice: a controversial concept - a focused review of literature. Nurse Education Today, 25(5), 355-362. http://dx.doi:10.1016/j.nedt.2005.03.002

Donoghue, J., Pelletier, S.D., 1991. An empirical analysis of a clinical assessment tool. Nurse Education Today 11, 354-362. http://dx.doi:10.1016/0202606917(91)90035-9

English, L., Jolly, B., Koutoukidis, G. Jenkins, S. 2014. Assessing undergraduate nursing students' integration of theory and practice within a capstone clinical stream. Office for Learning and Teaching, Sydney, Australia. Retrieved from http:// www.olt.gov.au

Franklin, N., Melville, P. 2015. Competency assessment tools: an exploration of the pedagogical issues facing competency assessment for nurses in the clinical environment. Collegian 22(1), 25-31. http://dx.doi:10.1016/j.colegn.2013.10.005

Fujimura, J. 1996. Crafting science: A sociohistory of the quest for the genetics of cancer. Harvard University Press, Cambridge, Massachusetts.

Gallagher, P., Smith, T., Ousey, K., 2012. Problems with competence assessment as it applies to student nurses. Nurse Education in Practice 12(6), 301-303. http://dx.doi:10.106/j.nepr.2012.05.014

Grealish, L. 2012. How competency standards became the preferred national technology for classifying nursing performance in Australia. Australian Journal of Advanced Nursing, 30(2), 20-31.

Grealish, L., Carroll, G. 1997. Beyond preceptorship and supervision: a third clinical teaching model emerges for Australian nursing education. Australian Journal of Advanced Nursing, 15(2), 3-11.

Heaslip, V., \& Scammell, J.M.E., 2012. Failing underperforming students: the role of grading in practice assessment. Nurse Education in Practice, 12(2), 95-100. http://dx.doi:10.1016/j.nepr.2011.08.003

Hutchison, T., Cochrane, J., 2014. A phenomenological study into the impact of the sign-off mentor in the acute hospital setting. Nurse Education Today, 34(6), 10291033. http://dx.doi:10.1016/j.nedt.2013.09.018

Kelly, J. 2005. Inter-rater reliability and Waterlow's pressure ulcer risk assessment tool. Nursing Standard,19(32), 86-92.

Levett-Jones, T., Lathlean, J., Higgins, I., McMillan, M. 2009. Staff-student relationships and their impact on nursing students' belongingness and learning. Journal of Advanced Nursing, 65(2), 316-324. http://dx.doi:10.1111/j.1365- 
2648.2008.04865.x

McAllister, M. 1998. Competency standards: clarifying the issues. Contemporary Nurse, 7(3), 1331-137. http://dx.doi:10.5172/conu.1998.7.3.131

Milligan, F. 1998. Defining and assessing competence: the distraction of outcomes and the importance of educational process. Nurse Education Today, 18(4), 273-280. http://dx.doi:10.1016/S0260-6917(98)80044-0

Molloy, E. K. 2010. The feedforward mechanism: A way forward in clinical learning? Medical Education, 44(12), 1157-1158. http://dx.doi:10.1111/j.13652923.2010.03868.x

Norman, I. J., Watson, R., Murrells, T., Calman, L., Redfern, S. 2002. The validity and reliability of methods to assess the competence to practise of pre-registration nursing and midwifery students. International Journal of Nursing Studies, 39(2), 133-145. http://dx.doi:10.1016/S0020-7489(01)00028-1

Ossenberg, C., Dalton, M., Henderson, A. 2016. Validation of the Australian Nursing Standards Assessment Tool (ANSAT): A pilot study. Nurse Education Today 36, 2330. http://dx.doi:10.1016/j.nedt.2015.07.012

Preston, B. Walker, J. 1993. Competency standards in the professions and higher education: a holistic approach. In C. Collins (Ed.), Competencies: the competencies debate in Australian education and training. Australian College of Education, Canberra, Australia, pp.116-130.

Star, S.L. Lampland, M. 2009. Reckoning with standards. In M. Lampland and S.L. Star (Eds). Standards and Their Stories: How Quantifying, Classifying and Formalizing Practices Shape Everyday Life. Cornell University Press, New York, NY, pp. 3-34.

Terry, K., Stirling, C., Bull, R., Fassett, D. 2017. An overview of the ways nurses understand and utilise the existing Australian Competency Standards for Registered Nurses. Collegian, 24(2), 109-116. http://dx.doi:org/1016/j.colegn.2015.10.003

Tilley, D.D.S., 2008. Competency in nursing: a concept analysis. The Journal of Continuing Education in Nursing, 39(2), 58-64.

Windsor, C., Douglas, C., Harvey, T. 2012. Nursing and competencies - a natural fit: the politics of skill/competency formation in nursing. Nursing Inquiry, 19(3), 213-222. http://dx.doi:10.1111/j.1440.1800.2011.00549.x

Wu, X.V., Enskar, K., Lee, C.C.S., Wang, W. 2015. A systematic review of clinical assessment for undergraduate nursing students. Nurse Education Today, 35(2), 347359. http://dx.doi:10.1016/j.nedt.2014.11.106

Yin, R.K. 2009. Case study research: design and methods (4th ed.). Thousand Oaks, Calif: Sage:

Zasadny, M.F., Bull, R.M. 2015. Assessing competence in undergraduate nursing students: The Amalgamated Students Assessment in Practice Model. Nurse Education in Practice, 15(2), 126-133. http://dx.doi:10.1016/j.nepr.2015.01.003 
Table 1. Proposed grading system

\begin{tabular}{lcccc} 
& Year 1 & Year 2 & Year 3/1 & Year 3/2 \\
\hline Number of items & 12 & 18 & 18 & 23 \\
with score of 3 or & & & & \\
higher & & & & \\
\end{tabular}

* Satisfactory (3) is consistent with entry-to-practice level 
Table 2. Proposed grading system

\begin{tabular}{|c|c|c|c|c|}
\hline & Year 1 & Year 2 & Year 3/1 & Year 3/2 \\
\hline Hurdle requirement: & 12 & 18 & 18 & 23 \\
\hline \multicolumn{5}{|l|}{ Number of items } \\
\hline \multicolumn{5}{|l|}{ with score of 3 or } \\
\hline \multicolumn{5}{|l|}{ higher } \\
\hline \multicolumn{5}{|l|}{ Score } \\
\hline High Distinction & $70+$ & $80+$ & $80+$ & $90+$ \\
\hline Distinction & $62-69$ & $71-79$ & $71-79$ & $83-89$ \\
\hline Credit & $56-61$ & $66-70$ & $66-70$ & $76-82$ \\
\hline Pass & $47-55$ & $62-65$ & $62-65$ & $69-75$ \\
\hline Fail & 46 or lower & 61 or lower & 61 or lower & 68 or lower \\
\hline
\end{tabular}

23 items

o Range 1-5

o Satisfactory performance on all categories indicates newly qualified nurse level e.g. ready to graduate 